\title{
Travel Times of Radionuclides Released from Hypothetical Multiple Source Positions in the KURT Site
}

\section{KURT 환경 자료를 이용한 가상의 다중 발생원에서의 누출 핵종의 이동 시간 평가}

Nak-Youl $\mathrm{Ko}^{1 *}$, Jongtae Jeong ${ }^{1}$, Kyung Su Kim ${ }^{1}$, and Youngtaek Hwang ${ }^{2}$

${ }^{1}$ Korea Atomic Energy Research Institute, 111 Daedeok-daero 989, Yuseong-gu, Daejon, Korea

${ }^{2}$ Chungnam National University, 99 Daehak-ro, Yuseong-gu, Daejon, Korea

고낙열 ${ }^{*}$, 정종태 ${ }^{1}$, 김경수 ${ }^{1}$, 황영택 2

1 한국원자력연구원, 대전광역시 유성구 대덕대로 989 번길111

2 충남대학교, 대전광역시 유성구 대학로 99

(Received August 16, 2013 / Revised September 23, 2013 / Approved October 28, 2013)

A hypothetical repository was assumed to be located at the KURT (KAERI Underground Research Tunnel) site, and the travel times of radionuclides released from three source positions were calculated. The groundwater flow around the KURT site was simulated and the groundwater pathways from the hypothetical source positions to the shallow groundwater were identified. Of the pathways, three pathways were selected because they had highly water-conductive features. The transport travel times of the radionuclides were calculated by a TDRW (Time-Domain Random Walk) method. Diffusion and sorption mechanisms in a host rock matrix as well as advection-dispersion mechanisms under the KURT field condition were considered. To reflect the radioactive decay, four decay chains with the radionuclides included in the high-level radioactive wastes were selected. From the simulation results, the half-life and distribution coefficient in the rock matrix, as well as multiple pathways, had an influence on the mass flux of the radionuclides. For enhancing the reliability of safety assessment, this reveals that identifying the history of the radionuclides contained in the high-level wastes and investigating the sorption processes between the radionuclides and the rock matrix in the field condition are preferentially necessary.

Keywords: Radionuclide transport simulation, Transport travel time, Multiple source positions, Sorption in a rock matrix, TDRW method

KURT(KAERI Underground Research Tunnel) 부지 부근에 가상의 처분장을 설정하고, 해당 부지의 세 지점에서 방사성폐 기물로부터 누출된다고 가정한 방사성 핵종의 이동 시간을 계산하였다. 핵종의 이동 경로는 핵종 누출 지점에서 천부 지하 수대까지로 설정하고 KURT 주변 지하수 유동계 모의를 통해 결정하였다. 세 지점은 지하수가 빠르게 유동하는 구조(highly water-conductive feature)를 지나가기 때문에 천부 지하수까지 도달하는데 상대적으로 적은 시간이 걸리는 지점으로 선정 되었다. 핵종의 이동 시간은 TDRW(Time-Domain Random Walk) 기법을 통해 계산하였다. 지하수 내의 핵종의 이동 시간 을 계산하기 위해, 이류(advection)와 분산(dispersion) 이외에 암반 기질(rock matrix)로의 확산(diffusion)과 기질 내부에 서의 흡착(sorption)이 고려되었고, 핵종의 붕괴 및 변환에 의한 영향도 몇 개의 붕괴 사슬(decay chain)을 이용하여 계산에 반영하였다. 계산 결과를 보면, 지표 부근의 천부 지하수에 도달하는 핵종의 시간당 이동량(mass flux)은 복수의 이동 경로 뿐만 아니라 핵종의 반감기와 암반 기질 내에서의 핵종의 흡착 분배 계수에 크게 영향을 받는 것으로 나타났다. 따라서 보 다 안정적이고 불확실성이 감소된 심지층 처분장의 안전성 평가를 위해 우선적으로 필요한 사항으로는, 장반감기 핵종에 대 한 평가가 이동 과정 이외에 저장 용기에 들어있는 상태에서부터 면밀하게 이루어져야 하고, 암반 기질에서 발생하는 핵종 
의 흡착 과정이 심부 현장 조건을 반영하여 평가되어야 할 것으로 생각된다.

중심단어 : 핵종 이동 모의, 용질 이동 시간, 다중 누출원, 암반 기질 내 흡착, 시간 차원 랜덤 워크 기법

*Corresponding Author.

Nak-Youl Ko, Korea Atomic Energy Research Institute, E-mail: nyko@kaeri.re.kr, Tel: +82.42.868.4929

\section{1.서 론}

고준위의 방사성폐기물을 처분하는 방안으로 여러 가 지 기법이 제시되었는데, 우리나라에서는 현재 심지층 처 분 관련 연구가 주로 이루어지고 있다[1,2]. 심지층 처분 에서는 처분용기에 들어있는 고준위 폐기물을 지하 심부 에 넣고 완충재(buffer) 등의 공학적 방벽(engineered barrier)으로 봉입하여 지표 환경과 격리한다. 처분용기가 지 하수에 의해 부식되거나 지진 등의 영향으로 처분용기 안 의 방사성핵종이 누출되면 공학적 방벽을 지나 천연 방벽 (natural barrier)에 해당하는 지하 암반 및 단열을 거쳐 지 표 환경에 도달할 수 있다. 이런 경우, 지하수가 핵종의 이 동 수단이 되기 때문에 심지층 처분장에 대한 안전성 평가 에서 처분 부지의 지하수 유동계는 매우 주의 깊게 분석되 어야 한다. 또한 핵종의 이동에 직접적으로 관여하는 이류 (advection), 분산(dispersion), 흡착(sorption) 특성에 대 한 조사도 핵종의 이동 거리 및 이동 시간 평가를 위해 필 요하다.

안전성 평가에 필요한 입력 자료 중에서 매우 중요 한 항목이기 때문에, 방사성 핵종의 이동 시간을 계산하 는 것에 대한 연구가 지금까지 이루어져 왔으며, 그 중 일 부 연구는 핵종의 이동 시간을 일반적인 공간 차원(spacedomain)에서가 아니라 시간 차원(time-domain)에서 계 산하는 기법을 이용하여 계산하였다[3-5]. 시간 차원에서 이동 시간을 계산하는 대표적인 기법으로 TDRW(TimeDomain Random Walk)가 있는데, 이 기법은 유체 내의 입자 운동을 확률변수로 표현하고, 이류와 분산을 통해 용 질 입자가 이동하여 공간에 분포되어 있는 상태가 시간에 따라 변화하는 양상을 표현한 방정식을 세워서 그 해를 통 해 이동 시간을 계산한다.

Banton 등[3]은 이류와 분산 기작에 의해 일정 거리 를 이동하는 지하수 내 용질의 이동 경과 시간을 TDRW
기법으로 평가하는 방법을 제시하였다. 이 연구에서는 유 체 내 입자의 임의적 운동(random displacement)에 의한 입자의 순간적인 이동을 확률 밀도 함수로 표현하여 그것 의 시간에 따른 변화를 시간 영역에서 계산하는 방식으로 TDRW 기법을 이용하였다. Delay와 Bodin[4]은 Banton 등[3]이 제안한 방식을 단열(fracture)과 암반 기질(rock matrix)로 이루어진 지하 매질에서 적용하기 위해 농도 차 이로 인한 암반 기질로의 확산 (matrix diffusion)을 고려할 수 있도록 시간 영역에서 제안된 식을 확장하고, 도출된 식 을 기존에 알려진 해석해와 비교하여 검증하였다. Bodin 등[5]은 확장된 시간 영역에서의 핵종 이동 경과 시간 계산 식을 2 차원의 단열망에 적용하여 계산하였다. 이 연구에 서는 단열이 교차하는 지점(fracture intersection)에서의 혼합(mixing) 형태를 완전 혼합(perfect mixing assumption)인 경우와 교차점에서 도달하는 유량의 비율로 혼합 이 일어나는 경우(stream-tube assumption)로 나누어 각 각에 대한 TDRW 계산을 수행하고 이를 해석해와 비교하 였다. Painter 등[6,7]은 핵종의 이동 시간을 이류 및 분산 에 의한 이동 시간과 흡착 등에 의해 지연되는 시간으로 구 분하고, 전자는 Banton 등[3]의 연구와 같이 이류-분산 방 정식을 시간 영역에서 변형시켜 계산하였다. 후자는 핵종 이 다공성 매질에서 이동할 경우에 대한 선형 흡착(linear sorption)과 단열 및 암반 기질로 이루어진 매질을 이동할 경우에 대한 암반 기질에 대한 확산 및 기질 내 흡착의 경 우로 나누고 각각에 대한 이동 지연 시간을 시간 영역에서 계산하는 방안을 제시하였다.

우리나라에서는 심지층 처분 연구를 위한 지하 환경 연구시설인 KURT(KAERI Underground Research Tunnel)의 건설을 전후로 하여 KURT 주변에 분포하는 결정 질 화강암층에 대한 여러 가지 조사와 연구가 시작되어 지 금까지 이루어지고 있다[8]. KURT의 건설이 완료된 이후 에는 부지 특성화(site characterization)를 위해 시설 내에 
Nak-Youl Ko. et al : Travel Times of Radionuclides Released from Hypothetical Multiple Source Positions in the KURT Site

서 여러 가지 조사와 현장 실험이 이루어졌고, 그것들을 통해 축적된 현장 자료를 이용하여 KURT 현장 주변에 대 한 지하수 유동계가 모의되었고 그 특성이 분석되었다[2]. 현장 조사 자료와 지하수 모의 결과 분석 자료 등은 KURT 환경에 가상의 처분장이 주어질 경우 그에 대한 안전성 평 가에 필요한 입력 자료로서 중요한 역할을 할 것으로 평 가되고 있다.

본 논문의 목적은 가상의 심지층 처분장의 복수의 위 치에서 누출되었다고 가정한 방사성핵종이 지하 환경을 거쳐 지표 부근까지 이동하는데 걸리는 시간을 계산하는 것이다. 가상의 처분장은 KURT 부지와 같은 환경에 존재 한다고 가정하였고, KURT의 현장 자료와 지하수 유동 분 석 자료를 이용하여 핵종의 이동 경로를 찾고, 해당 경로 를 따라 유동하는 지하수의 유속을 파악하였다. 경로의 길 이와 유속 자료를 바탕으로 TDRW 기법을 이용해 핵종의 이동 시간을 계산하였고, 계산에 이용된 붕괴 사슬에 포함 되어 방사성 붕괴에 의해 발생하는 핵종에 대한 이동 시간
도 함께 계산하였다. 마지막으로, 계산 결과를 통해 안전 성 평가의 불확실성을 줄이기 위해 필요한 사항을 고찰하 였고, 향후 심지층 처분장의 지질 조건과 지하수 유동 특성 이 파악되어 안전성 평가에 활용될 때, 핵종의 이동을 분석 하는 것에 대한 이용가능성을 살펴보았다.

\section{2. 연구 지역}

\section{1 수리지질학적 조건}

핵종의 이동 시간 계산을 위해 KURT 부근에서 조사 및 분석된 수리지질 및 지질 자료를 이용하였다. KURT는 고 준위 폐기물의 심지층 처분을 위한 지하 환경 연구 시설로 한국원자력연구원 부지 내에 건설되었다(Fig. 1). KURT 부지는 선캠브리아기의 화강편마암이 주로 분포되어 있 고, 쥬라기의 복운모 화강암도 높은 빈도로 나타난다. 지

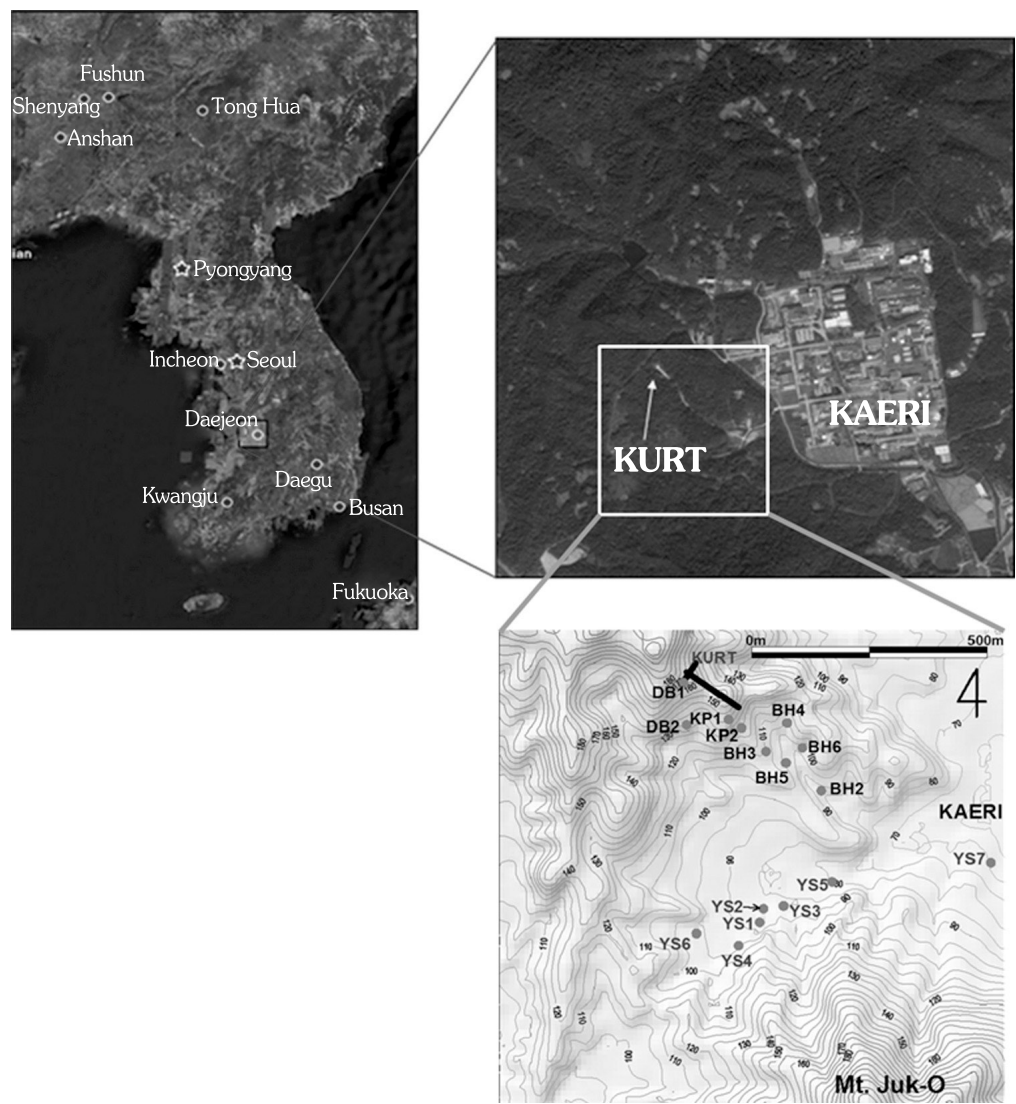

Fig. 1. Location of the study site. Characters in the lower maps mean observation boreholes $[2,9]$. 


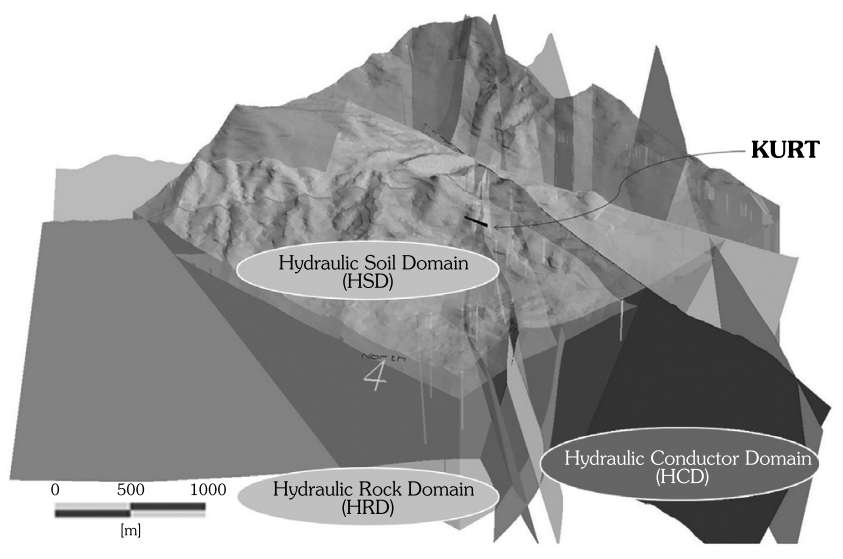

Fig. 2. Hydrogeological model around the KURT site [10].

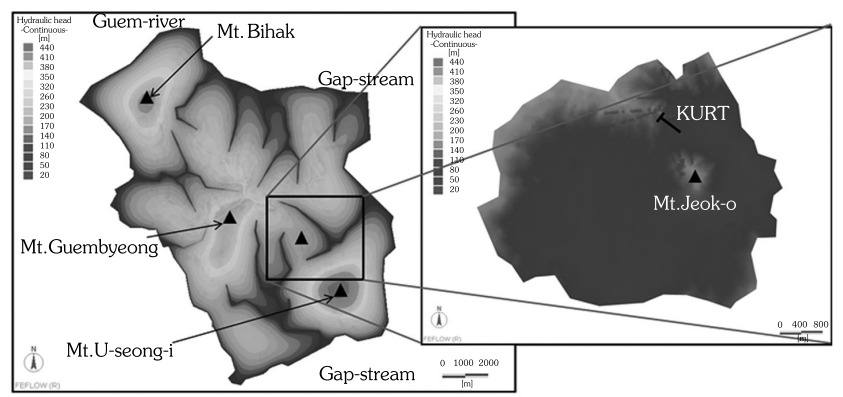

Fig. 3. Hydraulic head distributions of the regional and local scale models around the KURT site [12].

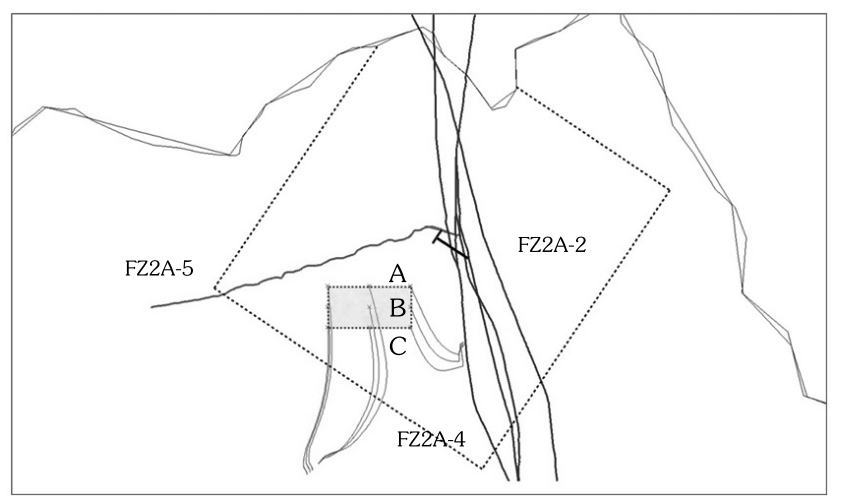

Fig. 4. Hypothetical repository at the depth of $500 \mathrm{~m}$ from the surface and the groundwater pathways from the repository simulated by the distribution of the hydraulic heads in the local scale groundwater flow model (modified from [2]). The symbols of "A", "B", and "C" represent the initial positions of the selected groundwater pathways, and the characters mean the fracture zones around the KURT facility.
표 조사, 지구 물리 탐사, 공내 탐사 등을 통해 KURT 부 지의 지질 모델이 구축되었다[9,10]. 지질 모델에서는 지 하 매질을 토양층, 풍화대, 단열대, 기반암으로 나누었고, 각각의 요소를 수리적 특성에 따라 수리토양대(hydraulic soil domain, HSD), 수리투수대(hydraulic conductive domain), 수리암반대(hydraulic rock domain)로 분류하 였다(Fig. 2). 그리고 각각의 수리적 특성을 반영하여 지하 수 유동 모델을 작성하였다[9].

KURT 부지의 지하수 유동계는 처음에 광역 규모에 대한 지하수 유동을 모의하였고, 광역 지하수 유동 모의 결과에서 경계 조건을 만들어 국지 모델을 작성하였다. 국 지 모델에는 KURT 부지가 포함되어 있으며, 광역 모델에 비해 보다 자세한 지하수 유동 모의가 이루어지도록 하였 다. 광역 모델에서의 지하수 유동 모의 결과를 보면, 지하 수는 지표의 고저를 따라 산지에서 강이 존재하는 방향 으로 주로 흐르고 있다고 분석되었다(Fig. 3). 광역 모델 의 모의값을 이용해 작성된 국지 모델에서의 지하수 유동 도 광역 규모와 마찬가지로 지형의 영향을 크게 받는 것으 로 나타났으나, 국지 모델에 반영된 단열 구조가 지하수면 과 지하수두 분포에 일부 영향을 끼치고 있는 것으로 나타 났다(Fig. 3).

\section{2 지하수 유동 경로}

KURT 주변의 국지적인 지하수 유동 환경 분석을 통 해, 가상의 심지층 처분장에서 지표 부근까지 이동하는 핵 종의 이동 경로를 파악하였다. 가상의 심지층 처분장은 KURT의 현장 자료와 분석, 지질 및 지질 공학 전문가들 의 검토를 거쳐 해수면 아래 $500 \mathrm{~m}$ 심도에 위치하는 것으 로 가정하였다[11]. 안전성 평가에 이용될 핵종의 이동 경 로를 구하기 위해 가상의 처분장에서 지표에 이르는 지하 수의 이동 경로를 계산하였는데, 지하수 유동 경로의 시작 점은 가상의 처분장의 외곽을 이용하였다(Fig. 4 ). 지하수 유동 경로는 지하수두의 차이를 이용하여 각 지점의 유량 을 계산한 자료를 이용하는 입자 추적 (particle tracking) 모의를 통해 분석하였다. 그리고 분석된 경로 중에서 지 하수가 빠르게 유동하는 구조(highly waster-conductive feature)가 되는 주변 단열대(FZ2A-4)를 통과하는 세 지점 $(\mathrm{A}, \mathrm{B}, \mathrm{C})$ 에서 누출되는 핵종이 안전성 평가에 가장 큰 영 향을 끼칠 수 있다고 간주하여 그 지점들을 시작 위치로 하 는 지하수 유동 경로를 핵종 이동 시간 모의에 이용하였 
Nak-Youl Ko. et al : Travel Times of Radionuclides Released from Hypothetical Multiple Source Positions in the KURT Site

다(Fig. 4).

\section{3. 지하수 핵종의 이동 시간 계산 방법}

\subsection{TDRW 방법}

\section{1 .1 이류-확산 과정에서의 이동 시간 계산}

공간 차원을 이용하여 지하수 내의 용질의 이동을 계 산하는 일반적인 방식과는 달리, TDRW 기법은 Lagrangian method를 따라 시간에 따른 용질의 상태 변화를 직 접적으로 계산하기 때문에 정해진 경로를 지나가는 용질 의 시간에 따른 변화를 계산하는데 더 효율적인 면을 보여 준다[3-7].

$x$ 방향을 따라 1 차원적으로 유동하는 유체 안에 용해된 상태로 존재하는 용질이 외부의 작용이 없는 상태에서 브 라운 운동(Brownian motion)과 같은 임의적인 운동(random displacement)에 의해 움직인다고 할 때, 용질이 일 정한 선속도(linear velocity) $v_{x}$ 와 분산 계수(dispersion coefficient) $D_{x}$ 에 따라 이동한다고 하면, 시간에 따른 용 질 입자의 위치 변화는 다음과 같은 Fokker-Planck 식으로 표현할 수 있다고 알려져 있다[3].

$$
\frac{\mathrm{af}}{\mathrm{at}}=v_{x} \frac{\mathrm{af}}{\mathrm{ax}}+\mathrm{D}_{x} \frac{\mathrm{a}^{2} \mathrm{f}}{\mathrm{ax}^{2}}
$$

이 때, $t$ 는 시간, $f$ 는 용질 입자 각각의 공간적 분포에 대한 임의의 변수(random variable)가 된다.

1 차원의 지하수 유동 경로를 따라 흐르는 용질이 이류와 분산에 의해 경로를 통과하는데 경과된 시간을 체류 시간 (residence time)이라고 하면, 유입 된 용질의 총량을 “ 1 "로 정규화(normalization)시켜 나타낸 용질의 시간에 따른 이 동량(mass flux)은 체류 시간에 대한 확률 밀도 함수의 형 태로 나타난다[3,6]. 그리고 확률 밀도 함수에 대한 누적 분 포는 식 (1)의 해석해의 형태로서 식 (2)와 같이 나타난다.

$F(\tau)=\frac{1}{2}\left[\operatorname{erfc}\left(\frac{\sqrt{\eta}}{2} \frac{1-\tau^{\prime}}{\sqrt{\tau^{\prime}}}\right)+\exp (\eta) \operatorname{erfc}\left(\frac{\sqrt{\eta}}{2} \frac{1-\tau^{\prime}}{\sqrt{\tau^{\prime}}}\right)\right]$

이 때, $\tau^{\prime}=\tau / \bar{\tau}, \tau$ 는 체류 시간, $\bar{\tau}$ 는 용질이 이류만으로 움 직일 때의 체류 시간 $\eta=L / \alpha, L$ 은 용질의 이동 거리, $\alpha$ 는 분산도이다.
식 (2)가 용질 입자 전체의 이동 시간에 대한 확률 밀도 함 수의 누적 분포이기 때문에, 특정한 용질 입자의 이동 시 간이 주어지면 그 입자가 전체 입자 중에서 얼마나 빨리 이동하였는가를 알 수 있다. 예를 들면, $F(\tau)$ 값이 0.2 이면 전체 입자 중에서 빨리 이동한 순서로 상위 $20 \%$ 에 해당한 다는 것이고, 0.95 이면 해당 입자가 이동하는데 걸린 시간 이 용질 전체의 $95 \%$ 가 이동하는데 걸린 시간이라는 것이 다. 이런 특성을 반대로 이용하면, 이동 시간이 적게 걸린 순서로 상위 $5 \%$ 에 해당하는 입자의 이동 시간은 $F(\tau)$ 값이 0.05가 되는 간단한 방정식의 풀이를 통해 알 수 있고, 총 입자의 $99 \%$ 가 이동하는데 걸리는 시간도 $F(\tau)$ 값을 0.99 로 하여 계산할 수 있다. TDRW 기법에서 이류와 분산에 의 한 체류 시간은 이와 같이 결정된다.

\subsection{2 암반 기질로의 확산에 의한 이동 시간의 지연}

이류와 분산에 의한 이동 시간 외에도, 지하수 내의 용 질 이동 시간을 지연시키는 과정이 시간 차원에서 고려되 었다. 특히 핵종이 단열 암반을 지나가는 경우 발생할 수 있는 암반 기질로의 확산과 기질 내에서의 흡착이 고려되 었는데, 앞의 이송-분산 과정과 마찬가지로 입자의 위치를 확률 밀도 함수로 갖는 방정식을 풀어서 시간에 대한 누적 분포로 식 (3)과 같이 표현하였다[13,14].

$$
\mathrm{F}\left(t_{\text {ret }} ; \mathrm{K}, \beta\right)=\operatorname{erfc}\left(\frac{\kappa \beta}{2 \sqrt{t_{\text {ret }}}}\right)
$$

이 때, $t_{r e t}$ 는 지연 시간(retention time), $\kappa=n_{i m} \sqrt{D^{*} R_{i m}}, n_{i m}$ 은 암반 기질의 공극률, $D^{*}$ 는 암반 기질로의 확산 계수 (diffusion coefficient), $R_{i m}$ 은 암반 기질에서의 지연 계수 (retardation factor), $\beta$ 는 수력학적 용질 이동 저항 변수로, $\beta=\int_{0}^{\tau} \frac{1}{b(\vartheta)} d \vartheta, b$ 는 단열의 간극 거리의 절반(half aperture)을 나타낸다[7].

식 (3)은 체류 시간을 계산할 때 식 (2)를 이용하는 것 과 같은 방식으로 암반 기질로의 확산에 의해 용질의 이동 시간이 얼마나 지연되는가를 계산하는데 이용된다. 따라 서 핵종의 붕괴 등으로 계산의 대상이 되는 핵종이 사라지 지 않는다면, 식 (3)은 흡착이 된 후 탈착(desorption)되어 나오는 시간을 나타내게 된다. 즉, 용질이 일정 구간을 이 동하는데 체류 시간 이외에 부가적으로 걸리게 되는 시간 을 식 (3)이 계산해 주는 것이 된다.

단열 암반에서 암반 기질로의 확산 및 기질에서의 흡 
Nak-Youl Ko. et al : Travel Times of Radionuclides Released from Hypothetical Multiple Source Positions in the KURT Site

Table 1. Groundwater pathways used in this study

\begin{tabular}{cccc}
\hline Pathways & $\begin{array}{c}\text { Travel } \\
\text { distance }(\mathrm{m})\end{array}$ & $\begin{array}{c}\text { Travel time } \\
(\mathrm{yr})\end{array}$ & $\begin{array}{c}\text { Number of } \\
\text { segments }\end{array}$ \\
\hline Path A & 897.5 & 1,763 & 113 \\
\hline Path B & 857.6 & 1,410 & 146 \\
\hline Path C & 829.8 & 1,914 & 88 \\
\hline
\end{tabular}

(Case 1) ${ }^{245} \mathrm{Cm} \rightarrow{ }^{241} \mathrm{Pu} \rightarrow{ }^{241} \mathrm{Am} \rightarrow{ }^{237} \mathrm{~Np} \rightarrow{ }^{233} \mathrm{U} \rightarrow{ }^{229} \mathrm{Th}$
$\left(\right.$ Case 2) ${ }^{234} \mathrm{Am} \rightarrow{ }^{239} \mathrm{Pu} \rightarrow{ }^{235} \mathrm{U} \rightarrow{ }^{231} \mathrm{Pu} \rightarrow{ }^{227} \mathrm{AC}$
$\left(\right.$ Case 3) ${ }^{240} \mathrm{Pu} \rightarrow{ }^{236} \mathrm{U} \rightarrow{ }^{232} \mathrm{Th} \rightarrow{ }^{228} \mathrm{Ra}$
$\left(\right.$ Case 4) ${ }^{246} \mathrm{Cm} \rightarrow{ }^{242} \mathrm{Pu} \rightarrow{ }^{238} \mathrm{U} \rightarrow{ }^{234} \mathrm{U} \rightarrow{ }^{230} \mathrm{Th} \rightarrow{ }^{226} \mathrm{Ra} \rightarrow{ }^{222} \mathrm{Rn}$
$\uparrow$
${ }^{238} \mathrm{Pu}$

Fig. 5. Decay chains used in this study.

착을 고려한 용질의 이동 시간은 이류와 분산에 의한 체 류 시간에 확산과 흡착에 의한 지연 시간을 더한 것으로 표현된다.

\subsection{TDRW 기법을 이용한 방사성 핵종의 이 동 시간 계산 알고리즘}

방사성 핵종 $A$ 가 붕괴되어 $B$ 로 변하고, 그 때의 붕괴 상수(decay constant)가 $\lambda$ 라고 하면, 하나의 이동로(segment)를 핵종 $A$ 와 $B$ 가 지나가는데 걸리는 이동 시간은 다 음의 과정을 통해 계산된다.

i. $R_{1} \in[0,1]$ 인 임의의 수(random number) $R_{1}$ 을 생 성하고 식 (2)에서 $F\left(\tau^{*}\right)=R_{1}$ 을 만족하는 $\tau^{*}$ 를 구한다. ii . 수력학적 용질 이동 저항 변수 $\beta^{*}$ 를 $\beta^{*}=\left(\tau^{*} / \bar{\tau}\right) \bar{\beta}$ 의 식으로 조정하여 분산의 영향을 반영한다 $(\bar{\beta}$ 는 체류 시 간이 $\bar{\tau}$ 인 경우의 수력학적 용질 이동 저항 변수).

iii. 지연 시간 $t_{r e t}$ 를 구하기 위해, $R_{2} \in[0,1]$ 을 만족하는 임의의 수 $R_{2}$ 를 생성한다. 식 (3)을 이용하여 핵종 $A$ 와 $B$ 에 대해 각각 $F^{-1}\left(R_{2} ; \kappa_{A}, \beta\right), F^{-1}\left(R_{2} ; \kappa_{B}, \beta\right)$ 을 계산하여 $t_{r e t, A}$ 와 $t_{r e t, B}$ 를 계산한다.

iv. 주어진 이동로에서의 핵종 $A$ 와 $B$ 에 대한 이동 시간 을 각각 $t_{A}=\tau^{*}+t_{r e t, A}, t_{B}=\tau^{*}+t_{r e t, B}$ 로 구한다.

$\mathrm{v}$. 또 다른 임의의 수 $R_{3}$ 를 $R_{3} \in[0,1]$ 에서 찾아서 방사
성 붕괴가 발생하는 시점 $t_{d}$ 를 $t_{d}=-\left(1 \mathrm{n} R_{3}\right) / \lambda$ 로 설정 한다.

vi. $t_{A}<t_{d}$ 이면 핵종 $A$ 에 대한 방사성 붕괴가 일어나지 않은 것이므로, 핵종의 총 이동 시간은 $t_{A}$ 로 결정된다. vii. $t_{A} \geq t_{d}$ 이면 방사성 붕괴에 의해 핵종 $A$ 가 $B$ 로 변환 된 것이므로, 이동로에서 각각의 핵종이 이동한 부분을 반영하여 총 이동 시간을 $t_{d}+\left(1-\left(t_{d} / t_{A}\right) t_{B}\right.$ 로 계산한다.

유입원에 일정한 개수의 핵종 입자를 설정해 두면, 위 의 알고리즘에 의해 일정 거리만큼 떨어진 지점에 도착하 는 입자의 이동 시간에 대한 누적 분포를 구할 수 있다. 핵 종의 총 유입량이 주어지면, 계산에 이용된 입자 하나가 나 타내는 양도 설정할 수 있게 된다. 이동로를 하나가 아닌, 여러 이동로가 서로 연결된 상황이라면, 앞선 이동로의 출 구에서 계산된 핵종의 총 이동 시간은 다음 이동로에서는 핵종의 초기 시간이 된다. 그리고 마지막 이동로의 출구에 서 계산된 입자의 이동 시간은 모든 이동로를 거쳤을 때의 총 이동 시간이 된다.

\section{TDRW 기법 적용 결과}

\section{1 입력 자료}

\subsubsection{TDRW 계산에 이용된 변수}

핵종의 이동 경로는 Fig. 4에 표시된 바와 같이 시작점 이 "A", "B", "C"인 세 경로가 선정되었고, 각 지점에서 지 표에 이르는 경로에 대한 전체 이동 거리와 지하수 유동에 걸리는 시간이 Fig. 4 의 국지 규모의 지하수 유동 모의 결 과를 통해 계산되었다. 각각의 핵종 이동 경로는 유한요 소(finite element) 수치모의영역의 각각의 요소를 연결하 는 이동로(segment)로 나누어졌고, TDRW 기법을 이용한 핵종의 이동 시간 모의에 입력값으로 활용되었다(Table 1). TDRW 기법을 활용하기 위해 필요한 다른 자료들은 KURT의 현장 자료[2], 스웨덴 SKB의 보고서[15], 참고 문 헌[11,14] 등을 이용하였고 Table 2에 정리하였다.

\section{1 .2 계산에 이용된 붕괴 사슬과 각 핵종의 흡착 계 수 및 초기 유입량}

처분될 것으로 예상되는 고준위 방사성 폐기물의 방 사성 핵종 중 일부는 몇몇 붕괴 사슬의 구성 원소이기도 하 며, 이런 방사성 핵종은 붕괴 사슬을 따라 다른 방사성 핵 
Nak-Youl Ko. et al : Travel Times of Radionuclides Released from Hypothetical Multiple Source Positions in the KURT Site

Table 2. Transport parameters used in the TDRW simulations

\begin{tabular}{lc}
\hline Parameter & Value \\
\hline Longitudinal dispersivity & $10 \%$ of the travel distance \\
\hline Bulk density & $2,650 \mathrm{~kg} / \mathrm{m}^{3}$ \\
\hline Porosity of the rock matrix & 0.0015 \\
\hline Porosity of the fracture zone & 0.02 \\
\hline Half aperture of the rock matrix & $0.0001 \mathrm{~m}$ \\
\hline Half aperture of the fracture zone & $0.001 \mathrm{~m}$ \\
\hline Diffusion coefficient in the rock matrix & $10^{-6} \mathrm{~m}^{2} / \mathrm{yr}$ \\
\hline
\end{tabular}

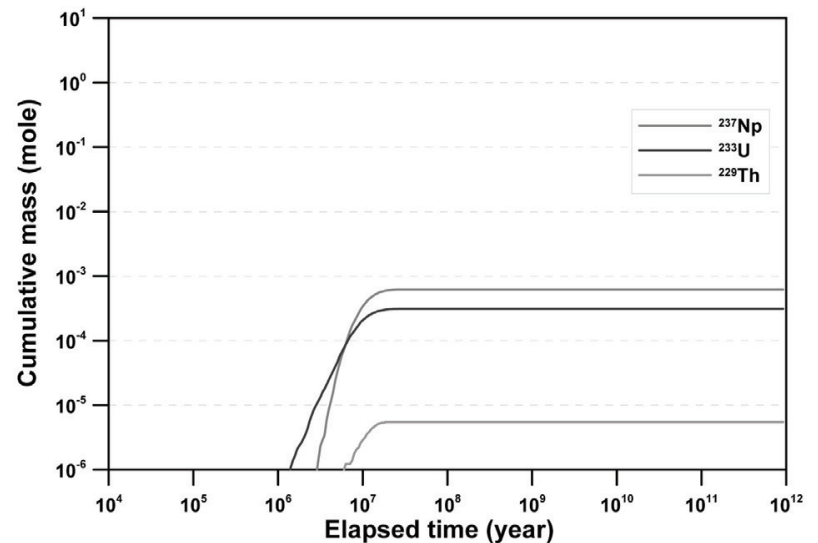

(a)

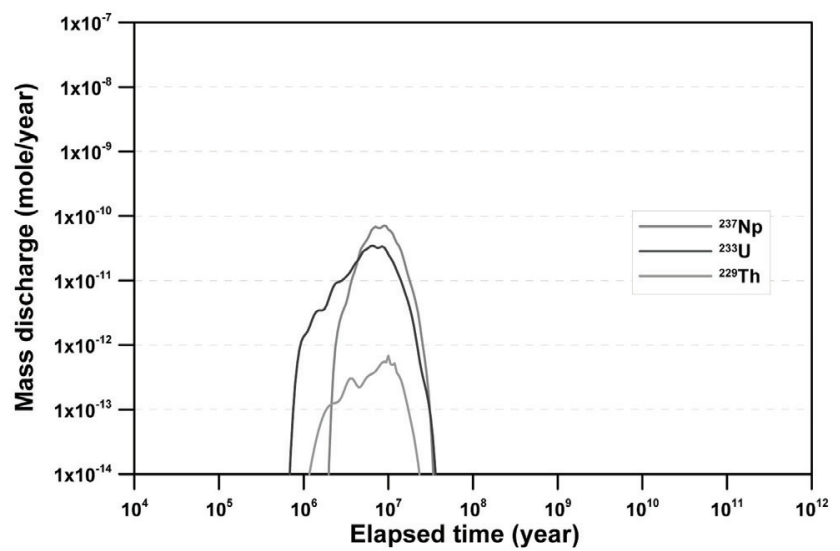

(b)

Fig. 6. TDRW simulation results in Case 1: (a) the cumulative distribution functions and (b) the breakthrough curves of the radionuclides included in the decay chain of Case 1.

종으로 전환되거나 안정한 원소로 변하기도 한다. 본 연 구에서는 KURT 환경에서의 방사성 핵종의 이동을 모의 하기 위해 A-KRS(Advanced Korean Reference Disposal

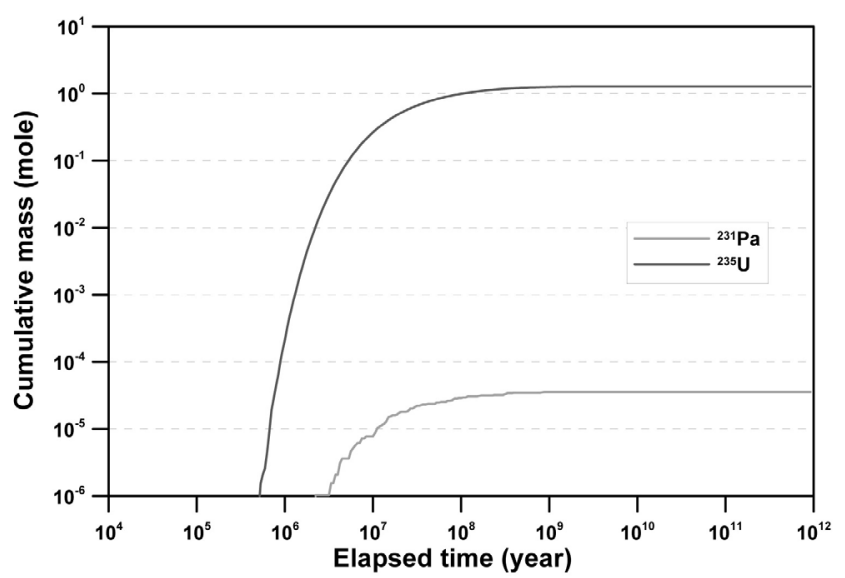

(a)

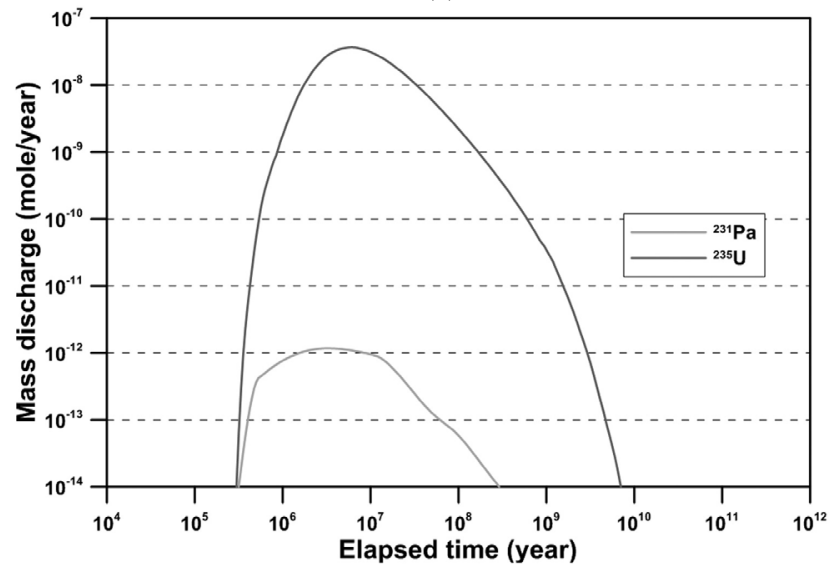

(b)

Fig. 7. TDRW simulation results in Case 2: (a) the cumulative distribution functions and (b) the breakthrough curves of the radionuclides included in the decay chain of Case 2.

System)에서 고려하는 고준위 폐기물에 포함된 붕괴 사슬 과 그 구성 핵종을 가상의 처분장에서 누출되는 핵종으로 가정하였다[2]. Fig. 5에 제시된 네 개의 붕괴 사슬이 선택 
Nak-Youl Ko. et al : Travel Times of Radionuclides Released from Hypothetical Multiple Source Positions in the KURT Site

Table 3. Half-lives, distribution coefficients, and initial mass of the radionuclides used in the TDRW simulations[2,11,14,15]

\begin{tabular}{|c|c|c|c|c|}
\hline Decay chain & Component & Half-life (yr) & $\begin{array}{l}\text { Distribution coefficient } \\
\qquad\left(\mathrm{m}^{3} / \mathrm{kg}\right)\end{array}$ & $\begin{array}{l}\text { Initial mass } \\
\quad(\text { mole })\end{array}$ \\
\hline \multirow{6}{*}{ Case 1} & ${ }^{245} \mathrm{Cm}$ & $8.50 \times 10^{3}$ & $4.00 \times 10^{-2}$ & $6.05 \times 10^{-4}$ \\
\hline & ${ }^{241} \mathrm{Pu}$ & $1.44 \times 10^{1}$ & $1.50 \times 10^{-2}$ & $2.02 \times 10^{-2}$ \\
\hline & ${ }^{241} \mathrm{Am}$ & $4.32 \times 10^{2}$ & $2.00 \times 10^{-2}$ & $1.37 \times 10^{-1}$ \\
\hline & ${ }^{237} \mathrm{~Np}$ & $2.14 \times 10^{6}$ & $2.00 \times 10^{-1}$ & $7.41 \times 10^{-2}$ \\
\hline & ${ }^{233} \mathrm{U}$ & $1.59 \times 10^{5}$ & $4.30 \times 10^{-2}$ & $9.32 \times 10^{-7}$ \\
\hline & ${ }^{229} \mathrm{Th}$ & $7.34 \times 10^{3}$ & $1.31 \times 10^{-1}$ & $7.33 \times 10^{-11}$ \\
\hline \multirow{5}{*}{ Case 2} & ${ }^{243} \mathrm{Am}$ & $7.38 \times 10^{3}$ & $2.00 \times 10^{-2}$ & $2.62 \times 10^{-2}$ \\
\hline & ${ }^{239} \mathrm{Pu}$ & $2.14 \times 10^{4}$ & $1.50 \times 10^{-2}$ & $5.15 \times 10^{-1}$ \\
\hline & ${ }^{235} \mathrm{U}$ & $7.04 \times 10^{8}$ & $4.30 \times 10^{-2}$ & $5.91 \times 10^{-4}$ \\
\hline & ${ }^{231} \mathrm{~Pa}$ & $3.28 \times 10^{4}$ & $5.90 \times 10^{-2}$ & $1.15 \times 10^{-11}$ \\
\hline & ${ }^{227} \mathrm{Ac}$ & $2.18 \times 10^{1}$ & $1.50 \times 10^{-2}$ & $2.43 \times 10^{-15}$ \\
\hline \multirow{4}{*}{ Case 3} & ${ }^{240} \mathrm{Pu}$ & $6.54 \times 10^{3}$ & $1.50 \times 10^{-2}$ & $2.54 \times 10^{-1}$ \\
\hline & ${ }^{236} \mathrm{U}$ & $2.34 \times 10^{7}$ & $4.30 \times 10^{-2}$ & $1.08 \times 10^{-3}$ \\
\hline & ${ }^{232} \mathrm{Th}$ & $1.41 \times 10^{10}$ & $1.31 \times 10^{-1}$ & $6.26 \times 10^{-10}$ \\
\hline & ${ }^{228} \mathrm{Ra}$ & $5.75 \times 10^{0}$ & $2.40 \times 10^{-4}$ & None \\
\hline \multirow{8}{*}{ Case 4} & ${ }^{246} \mathrm{Cm}$ & $4.73 \times 10^{3}$ & $4.00 \times 10^{-2}$ & $8.66 \times 10^{-5}$ \\
\hline & ${ }^{242} \mathrm{Pu}$ & $3.75 \times 10^{5}$ & $1.50 \times 10^{-2}$ & $8.43 \times 10^{-2}$ \\
\hline & ${ }^{238} \mathrm{U}$ & $4.47 \times 10^{9}$ & $4.30 \times 10^{-2}$ & $6.22 \times 10^{-6}$ \\
\hline & ${ }^{238} \mathrm{Pu}$ & $8.77 \times 10^{1}$ & $1.50 \times 10^{-2}$ & $2.53 \times 10^{-2}$ \\
\hline & ${ }^{234} \mathrm{U}$ & $2.45 \times 10^{5}$ & $4.30 \times 10^{-2}$ & $9.64 \times 10^{-3}$ \\
\hline & ${ }^{230} \mathrm{Th}$ & $7.70 \times 10^{4}$ & $1.31 \times 10^{-1}$ & $6.04 \times 10^{-7}$ \\
\hline & ${ }^{226} \mathrm{Ra}$ & $1.60 \times 10^{3}$ & $2.40 \times 10^{-4}$ & $7.12 \times 10^{-11}$ \\
\hline & ${ }^{222} \mathrm{Rn}$ & $1.05 \times 10^{-2}$ & 0 & None \\
\hline
\end{tabular}

되었고, 붕괴 사슬에 포함된 핵종의 반감기와 암반 기질에 서의 분배 계수(distribution coefficient)는 Table 3 에 정 리하였다.

붕괴 사슬에 포함되어 이동 시간 계산에 쓰인 핵종들 은 모두 유입원에서 일시적으로 누출된 것으로 가정하였 다. 초기 유입량은 Table 3에 정리되어 있다. Table 3에 표 시된 초기 유입량은 한 지점의 처분용기에서 누출된 양이 므로, 모의에서는 총 세 개의 처분용기에서 누출이 일어난
것으로 설정되어 계산되었다.

\section{2 이동 시간 모의 결과}

네 가지의 붕괴 사슬에 대해서 각각의 붕괴 사슬을 이 루는 핵종들의 이동 시간을 방사성 붕괴를 반영하여 계산 하였다. 세 지점에서 유출된 핵종이 이동하여 천부 지하수 에 도달하는 핵종의 총 이동량에 대한 결과는 Fig. 6에서 


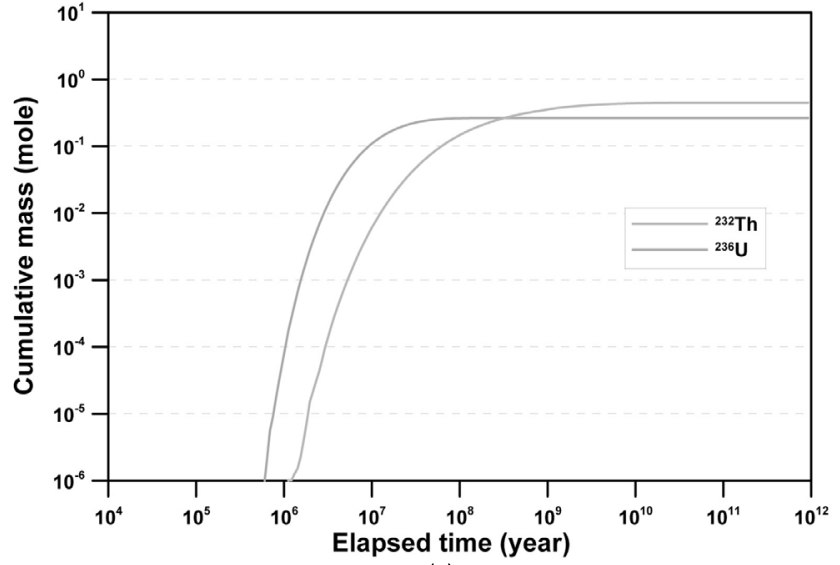

(a)

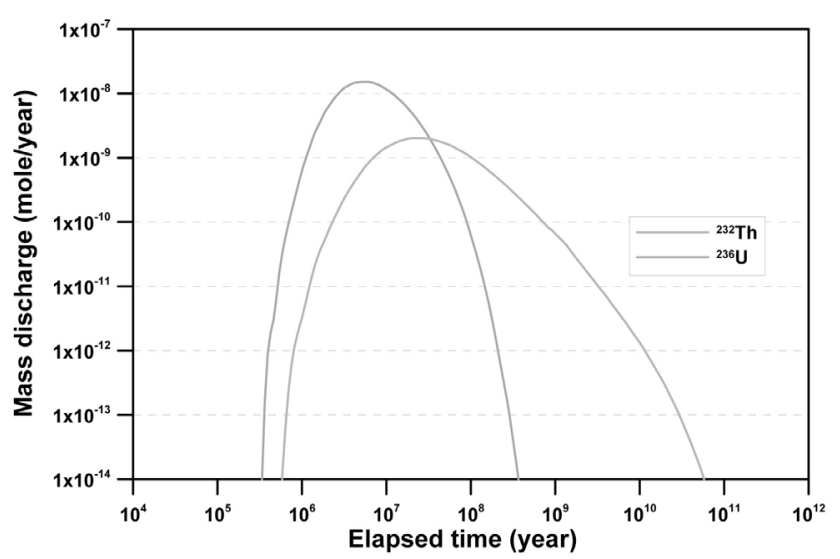

(b)

Fig. 8. TDRW simulation results in Case 3: (a) the cumulative distribution functions and $(\mathrm{b})$ the breakthrough curves of the radionuclides included in the decay chain of Case 3.

Fig. 9에 걸쳐 도시하였다.

Case 1 의 경우, ${ }^{233} \mathrm{U}$ 가 $10^{6}$ 년을 지난 시점에서 가장 먼 저 도달한 후에 ${ }^{229} \mathrm{Th}$ 와 ${ }^{237} \mathrm{~Np}$ 가 천부 지하수에 나타난다 (Fig. 6). ${ }^{245} \mathrm{Cm},{ }^{241} \mathrm{Pu},{ }^{241} \mathrm{Am}$ 은 천부 지하수에 도달하지 못하는데 상대적으로 짧은 반감기와 흡착에 의한 것으로 생각된다. ${ }^{241} \mathrm{Pu}$ 는 반감기가 매우 짧아 흡착되지 않더라도 이동 경로를 지나는 동안에 모두 붕괴되고, ${ }^{241} \mathrm{Am},{ }^{245} \mathrm{Cm}$ 은 암반 기질에 흡착되어 발생하는 지연 시간에 의해 붕괴 되는 것으로 나타난다. 비슷한 반감기를 갖는 ${ }^{229} \mathrm{Th}$ 는 초 기에 유입된 양이 아니라 ${ }^{237} \mathrm{~Np}$ 와 ${ }^{233} \mathrm{U}$ 의 붕괴 산물이 천부 지하수에 도달한 것으로 보인다.

Case 2의 경우, 초기 유입량이 제일 많은 ${ }^{243} \mathrm{Am}$ 과 ${ }^{239} \mathrm{Pu}$ 는 짧은 반감기로 인해 천부 지하수에 다다르지 못

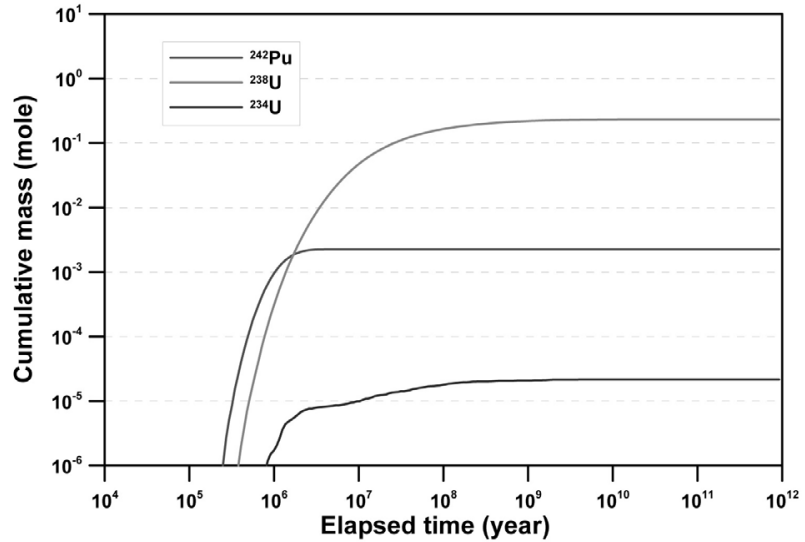

(a)

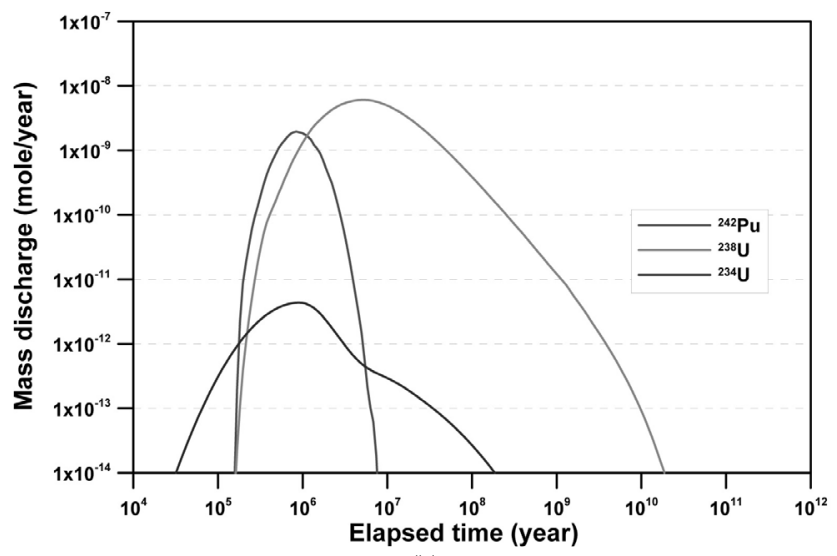

(b)

Fig. 9. TDRW simulation results in Case 4: (a) the cumulative distribution functions and (b) the breakthrough curves of the radionuclides included in the decay chain of Case 4.

한다(Fig. 7). 반감기가 매우 긴 ${ }^{235} \mathrm{U}$ 는 많은 양이 천부 지 하수로 도달하는데, ${ }^{239} \mathrm{Pu}$ 가 붕괴되어 생성된 것들이 대부 분을 차지하는 것으로 나타난다. ${ }^{235} \mathrm{U}$ 의 붕괴에 의해 생성 된 ${ }^{231} \mathrm{~Pa}$ 도 나타나지만, ${ }^{231} \mathrm{~Pa}$ 의 반감기가 짧은 편이어서 그 리 많은 양이 도달하지는 못한다. 같은 이유로 ${ }^{231} \mathrm{~Pa}$ 의 붕 괴 산물인 ${ }^{227} \mathrm{Ac}$ 는 천부 지하수에 나타나지 않는 것으로 계 산되었다.

Case 3의 경우, 반감기가 $10^{7}$ 년을 넘어가는 ${ }^{236} \mathrm{U}$ 와 ${ }^{232} \mathrm{Th}$ 만이 천부 지하수까지 이동한다(Fig. 8). 초기 유입 량이 극히 적기 때문에, ${ }^{232} \mathrm{Th}$ 는 대부분 ${ }^{236} \mathrm{U}$ 의 붕괴 산물 인 것으로 생각된다. 시간에 따른 이동량을 분석해 보면, ${ }^{232} \mathrm{Th}$ 가 ${ }^{236} \mathrm{U}$ 보다 천부 지하수에 도달하여 나타나는 시간 의 폭이 더 크게 나타나는데, 이는 ${ }^{232} \mathrm{Th}$ 의 분배 계수가 더 
커서 지연 시간이 늘어나 생기는 현상으로 생각된다.

Case 4 의 경우, 천부 지하수까지 가장 많은 양이 이 동하는 것은 반감기가 가장 긴 ${ }^{238} \mathrm{U}$ 인데, 초기 유입량 보다 는 ${ }^{242} \mathrm{Pu}$ 의 붕괴 산물인 것으로 보인다. 다른 핵종에 비해 초기 유입량이 매우 큰 ${ }^{242} \mathrm{Pu}$ 는 반감기도 $10^{5}$ 년을 넘기 때 문에 일부가 천부 지하수까지 도달하고 있다. ${ }^{234} \mathrm{U}$ 는 약간 특이한 시간당 이동량을 보이는데, 이는 누출의 초기 부분 은 초기 유입량이 Case 4 에 속하는 다른 핵종에 비해 상 대적으로 많은 ${ }^{238} \mathrm{Pu}$ 의 붕괴 산물이 이동한 것으로 보이 며, $10^{6}$ 년 이후의 부분은 ${ }^{238} \mathrm{U}$ 의 붕괴 산물이 도달하는 것 으로 생각된다. 다른 핵종들은 반감기로 인해 천부 지하 수에 도달하기 전에 붕괴되어 안정한 원소로 전환된 것으 로 생각된다.

\section{5. 결론}

향후 심지층 처분 부지가 결정되어 부지의 수리지질학 적 특성이 파악된 후, 안전성 평가에 필요한 방사성핵종의 이동 양상을 분석하는데 적용할 수 있는 방안을 개발하고 그 이용가능성을 알아보기 위해, KURT 부지의 지질 및 수 리지질 자료를 통해 분석된 지하수 유동 환경을 통해 가상 의 지하 처분장에서 천부 지하수에 도달하는 지하수의 유 동 경로가 파악되었고, 고준위 폐기물에서 누출되어 그 경 로를 따라 이동할 것으로 가정된 방사성 핵종의 이동 시간 을 TDRW 기법을 이용하여 계산하였다. 네 가지 경우의 붕 괴 사슬이 선택되어 각 붕괴 사슬을 이루는 핵종의 이동 시 간을 모의하였고, 이류와 분산에 의한 이동 외에 암반으로 의 확산과 기질 내에서의 흡착에 의한 영향도 반영하였다.

TDRW 기법으로 계산된 결과를 보면, 핵종 이동 경로 의 끝 부분으로, 핵종의 도달 지점에 해당하는 천부 지하수 에 핵종이 나오기 시작하는 시점이나 핵종이 나오는 기간, 핵종의 총 유출량에 영향을 크게 주는 요소는 반감기와 암 반 기질에서의 흡착을 나타내는 분배 계수로 생각된다. 암 반 기질로의 확산과 기질 내에서의 흡착에 의해 발생하는 지연 시간에 의해 핵종의 이동 시간이 매우 길어지게 되어 유출 지점에 도착하는 시간이 늦어지게 되고, 유출이 지속 되는 시간도 늘어나게 된다. 이런 경우에 반감기가 짧은 핵 종은 유출 지점에 도달하기 전에 붕괴되어 다른 핵종이나 안정한 원소로 전환되기 때문에 나타나지 않게 되며, ${ }^{236} \mathrm{U}$ 나 ${ }^{232} \mathrm{Th}$ 와 같이 반감기간 긴 핵종의 경우는 도달 시간 지 연이나 유출 지속 시간의 증가 현상이 그대로 나타나게 된
다. 이외에도, 핵종이 유입되는 지점의 차이나 붕괴 사슬 에서 동일한 핵종이 서로 다른 핵종의 붕괴에 의해 발생되 는 현상으로 인한 유출 시점의 차이도 나타났다.

방사성 핵종의 누출이 복수의 장소에서 발생하는 경 우, 각 장소에 대한 지하수 유동 경로 분석 자료와 함께, 암 반 기질에서의 흡착 과정이 최종 유출 지점에 도달하는 시 점과 핵종 유출이 지속되는 기간에 영향을 주고 있으므로 그에 대한 정보를 제공하는 현장 자료가 요구되며, 핵종의 반감기가 핵종의 유출 여부 및 유출량에 직접적인 영향을 주고 있기 때문에 고준위폐기물에 포함된 핵종의 생성 및 붕괴 시간에 대한 보다 자세한 정보가 필요할 것으로 생각 된다. 핵종 이동에 끼치는 영향이 크기 때문에, 안전성 평 가의 불확실성을 효율적으로 개선하기 위해서는 이런 요 소들에 대한 연구가 다른 사항보다 우선적으로 이루어져 야 할 것으로 생각된다.

마지막으로, 방사성핵종의 이동량은 지하 환경의 불 확실성에도 크게 영향 받을 수 있으나 본 연구에서는 핵종 의 이동 경로를 결정론적으로 가정하여 이동 경과 시간을 계산하였다. 지질 및 수리지질학적 불확실성을 고려하기 위해 지하수 유동 경로를 확률적 분포로 작성하여 핵종의 이동을 계산할 수 있다면 현장 조건이 더 많이 반영된 모의 결과를 얻을 수 있고, 불확실성이 보다 감소된 안전성 평가 를 수행할 수 있을 것으로 생각된다.

\section{감사의 글}

본 논문은 미래창조과학부에서 시행하는 원자력연구 개발사업의 일환으로 한국연구재단의 지원을 받아 수행 되었습니다.

\section{REFERENCES}

[1] C.H. Kang, "Current Status of Radioactive Waste Management in Korea", Journal of Hydrologic Engineering, 14(11), pp. 1197-1199 (2009).

[2] KAERI (Korea Atomic Energy Research Institute), "Geological Disposal of Pyroprocessed Waste from PWR Spent Nuclear Fuel in Korea", KAERI/TR4525/2011, KAERI (2011).

[3] O. Banton, F. Delay, and G. Pore, "A New Time 
Domain Random Walk Method for Solute Transport in 1-D Heterogeneous Media", Ground Water, 35(6), pp. 1008-1013 (1997).

[4] F. Delay and J. Bodin, "Time Domain Random Walk Method to Simulate Transport by Advection-Dispersion and Matrix Diffusion in Fracture Networks", Geophysical Research Letters, 28(21), pp. 40514054 (2001).

[5] J. Bodin, G. Porel, and F. Delay, "Simulation of Solute Transport in Discrete Fracture Networks Using the Time Domain Random Walk Method", Earth and Planetary Science Letters, 208, pp. 297-304 (2003).

[6] S.L. Painter, V. Cvetkovic, and O. Pensado, "TimeDomain Random Walk Algorithm for Simulating Radionuclide Transport in Fractured Porous Rock", Nuclear Technology, 163(1), pp. 129-136 (2008).

[7] S. Painter, V. Cvetkovic, J. Mancillas, and O. Pensado, "Time-Domain Particle Tracking Methods for Simulating Transport with Retention and First-Order Transformation", Water Resources Research, 44, W01406, doi:10.1029/2007WR005944 (2008).

[8] W.J. Cho, S.K. Kwon, and J.H. Park, "KURT, A Small-Scale Underground Research Laboratory for the Research on a High-Level Waste Disposal", Annals of Nuclear Energy, 35(1), pp. 132-140 (2008).

[9] K.W. Park, Y.K. Koh, K.S. Kim, and J.W. Choi, "Construction of the Geological Model around KURT area based on the surface investigations", J. Korean Radioact. Waste Soc., 7(4), pp. 191-205 (2009).

[10] K.W. Park, K.S. Kim, Y.K. Koh, and J.W. Choi, "Synthetic Study on the Geological and Hydrogeological Model around KURT", J. Korean Radioact. Waste Soc., 9(1), pp. 13-21 (2011).

[11] K.S. Kim, K.W. Park, G.Y. Kim, and H.J. Choi, "Development of Advanced Korean Reference HLW Disposal System - Site Characteristics", KAERI/TR-4265/2011, KAERI (2011).

[12] N.Y. Ko, K.W. Park, K.S. Kim, and J.W. Choi, "Groundwater Flow Modeling in the KURT site for a Case Study about a Hypothetical Geological
Disposal Facility of Radioactive Wastes", J. Korean Radioact. Waste Soc., 10(3), pp. 143-149 (2012).

[13] V. Cvetkovic, J.O. Selroos, and H. Cheng, "Transport of Reactive Tracers in Rock Fractures", Journal of Fluid Mechanics, 378, pp. 335-356 (1999).

[14] C. Zheng and G.D. Bennett, Applied Contaminant Transport Modeling, 2nd ed., p. 621, John Wiley and Sons, Inc., New York (2002).

[15] SKB, Data Report for the Safety Assessment SRSite, TR-10-52, SKB (2010). 